\title{
Norwich Terrier
}

National Cancer Institute

\section{Source}

National Cancer Institute. Norwich Terrier. NCI Thesaurus. Code C53727.

The Norwich Terrier is among the smallest of the working terriers. It has a short, strong, sturdy body with strongly boned legs and a fox-like muzzle. Their coats are wiry and straight and come in red, wheaten, tan, black and tan, and grizzle - occasionally with white markings. Height: 10 inches (25 cm.) Weight: 10-12 pounds (4.5-5.5 kg.) 